\title{
Type 2 diabetes mellitus is associated with lower serum adiponectin level in Bangladeshi population
}

\author{
SN Eva1 ${ }^{1}$, GM Molla² ${ }^{2}$ DK Sunyal ${ }^{3}$, R Zinnat $^{4}$
}

\begin{abstract}
The aim of the observational case control study was to find out the association of type 2 diabetes mellitus (T2DM) with serum adiponectin level in Bangladeshi population. This was conducted in the Biomedical Research Group, Research Division, Bangladesh Institute of Research and Rehabilitation in Diabetes, Endocrine and Metabolic Disorders (BIRDEM), Dhaka, Bangladesh. Sixty six T2DM subjects and seventy four healthy control subjects were included. Diabetes was diagnosed and classified as per World Health Organization criteria. Serum adiponectin was measured by Enzyme Linked Immunosorbent Assay (ELISA) method. Serum glucose was measured by glucose-oxidase method; serum insulin was measured by chemiluminescence- based ELISA technique. The insulin secretory capacity (HOMA\%B), insulin sensitivity (HOMA\%S) \& insulin resistance (HOMA-IR) were assayed by homeostasis model assessment method. Statistical analysis was performed using SPSS Windows version 11.5. The median (range) fasting serum insulin of control and T2DM subjects were 14.7 (1.9-45.9) and 18.1 (4.1-42.8), respectively. The median (range) serum adiponectin $(\mu \mathrm{g} / \mathrm{ml})$ of the control and T2DM subjects were 8.7 (0.8-16.0) and 6.2 (1.1-22.4). The serum adiponectin of T2DM was significantly lower than the control subjects $(p<0.001)$. The median (range) HOMA\%B values of control and T2DM subjects were 160.1 (33.4-493.4) and 100.5 (17.7-349.3), respectively. The median HOMA\%B of T2DM subjects was significantly lower than the control subjects ( $\mathrm{p}<$ 0.001 ). The median (range) HOMA\%S values of control and T2DM subjects were 44.2 (9.8-339.4) and 32.8 (14.3-154.7), respectively. The median HOMA\%S of T2DM group was significantly lower than the control subjects $(p<0.05)$. The median (range) HOMA-IR of control and T2DM subjects were $3.5(0.5-11.4)$ and 5.8 (1.0-28.3), respectively. The median HOMA-IR of T2DM subjects was significantly higher than the control subjects $(p<0.001)$. The results of the study suggest that T2DM subjects have both insulin secretory defects, insulin resistance and associated with lower serum adiponectin level in Bangladeshi population.
\end{abstract}

Key words: Type 2 diabetes mellitus, adiponectin, insulin sensitivity, insulin resistance.

\section{Introduction}

Diabetes mellitus (DM) is a lifelong disease and requires daily treatment. It has been estimated that the total number of diabetic patients in Bangladesh was more than 3 million in 2000, and this number would rise to 11.1 million by the 2030 . The proportional increase in Bangladesh seems relatively

\footnotetext{
1. SN Eva, Assistant Professor, Department of Biochemistry, Ashiyan Medical College, Dhaka

2. GM Mollah, Professor, Department of Biochemistry, Gazi Medical College, Khulna

3. DK Sunyal, Professor, Department of Physiology, Gazi Medical College, Khulna

4. R Zinnat, Associate Professor, Department of Biochemistry \& Cell Biology, BIRDEM, Dhaka
} 
higher compared to other Asian countries. ${ }^{1}$ An epidemiological study has revealed that the prevalence of DM in Bangladesh had increased exponentially in urban and rural populations which is double in urban than in rural areas ( $8 \%$ vs $4 \%$ ) and rises with affluence. $^{2}$ Age adjusted prevalence of type 2 DM (T2DM) was about 5.6\% among the rural population. ${ }^{3}$ This creates a great challenge to health care system in developing country like Bangladesh.

Several pathogenic processes are involved in the development of diabetes. These range from autoimmune destruction of pancreatic $\beta$-cells with consequent insulin deficiency to abnormalities that result in resistance to insulin action. Impairment of insulin secretion and defects in insulin action frequently coexist in the same patient, and it is often unclear which abnormality, if either alone, is the primary cause of the hyperglycemia. ${ }^{4}$ Excess adiposity is one of the most important risk factor for the development of insulin resistance and T2DM.5 Adipose tissue, in addition to being a fat store, secretes a number of hormones and proteins collectively termed adipokines. $^{6,7}$ Of all the adipokines, adiponectin has drawn special attention, largely due to its effects on both insulin sensitivity and inflammation. ${ }^{8}$ In healthy non-obese subjects, the plasma level of adiponectin ranges from 4 to $14 \mu \mathrm{g} / \mathrm{mL}$ and the blood level from 4 to $30 \mu \mathrm{g} / \mathrm{mL}$. $^{9-11}$ Although the physiological role of adiponectin is yet to be determined, it has been suggested that it has protective effects against the development of atherosclerosis. ${ }^{12,13}$ Animal studies and cell culture experiments have shown that direct stimulation of nitric oxide synthesis is responsible for the anti-inflammatory mechanism and antiatherogenic effects of adiponectin. ${ }^{14,15}$ These clinical and experimental observations suggest that adiponectin plays some protective role against the atherosclerotic vascular change and decreased plasma adiponectin in T2DM patients may contribute to the development of atherosclerotic complications. ${ }^{16}$ Though adiponectin has no effect on normal insulin secretion, but diminishes the pro-apoptotic effects of cytokines and free fatty acids on $\beta$-cells. ${ }^{16}$ A prospective study shows that higher adiponectin levels are consistently associated with a lower risk of T2DM across diverse populations. ${ }^{17}$ Low concentration of adiponectin predicted subsequent development of impaired glucose regulation (IGR) and T2DM in initially normoglycemic middle aged people. ${ }^{18}$ Low adiponectin is shown to be predictive of future diabetes in many populations, including the Asian and Indians. ${ }^{19,20}$ It is now established that, adiponectin is one of the strongest and most consistent biochemical predictors of T2DM. ${ }^{21}$

In a series of studies on Bangladeshi population to investigate the basic defects of T2DM both insulin secretory defect and insulin resistance had been found. ${ }^{22-24}$ Another study of Bangladeshi population has showed that subclinical inflammation evidenced in T2DM is associated with insulin resistance but not with insulin secretory defect. ${ }^{25}$ In a recent study in Bangladesh, it was found that ratio of fasting glucose to adiponectin may be an important factor for the development of T2DM and associated with insulin sensitivity and insulin secretory capacity in pre-diabetic or IGR subjects. ${ }^{26}$ As serum adiponectin is a good predictor of T2DM and serum adiponectin level has not yet been investigated in Bangladeshi T2DM subjects. So this study has been undertaken to find out the level of serum adiponectin in Bangladeshi T2DM subjects.

\section{Materials and Method}

This observational case control study was conducted in the Biomedical Research Group, Research Division, Bangladesh Institute of Research and Rehabilitation in Diabetes, Endocrine and Metabolic Disorders (BIRDEM), Dhaka, Bangladesh from July 2011 to June 2012. A total of 140 subjects were recruited in this study irrespectively of race, religion and socioeconomic status. Out of 140,74 subjects were healthy control and 66 were T2DM patients who were body mass index 
(BMI) matched. DM was diagnosed and classified as per World Health Organization criteria. Serum adiponectin was measured by Enzyme Linked Immunosorbent Assay (ELISA) method. Serum glucose was measured by glucose-oxidase method. Serum insulin was measured by chemiluminescence-based ELISA technique. The insulin secretory capacity (HOMA\%B), insulin sensitivity (HOMA\%S) and insulin resistance (HOMA-IR) were assayed by homeostasis model assessment method. The data were analyzed by univariate, bivariate and multivariate statistical tests.

\section{Results}

The mean BMI $( \pm S D)$ of control subjects and T2DM patients were $25.0( \pm 3.6)$ and 25.9 $( \pm 3.6)$. The mean age $( \pm S D)$ of the control subjects and T2DM patients were $42.5( \pm 9.2)$ and $48.5( \pm 8.1)$ years (Table 1$)$. The median (range) fasting serum insulin $(\mu \mathrm{lU} / \mathrm{mL}$ ) of control subjects and T2DM patients were 14.7 (1.9-45.9) and 18.1 (4.1-42.8) (Table 2).
The median (range) serum adiponectin $(\mu \mathrm{g} / \mathrm{mL})$ of the control subjects and T2DM patients were $8.7(0.8-16.0)$ and 6.2 (1.1-22.4) (Fig. 1). The serum adiponectin level of T2DM patients was significantly lower than the control subjects $(p<0.001)$. The median (range) HOMA\%B values of control subjects and T2DM patients were 160.1 (33.4-493.4) and 100.5 (17.7-349.3), respectively. The median $\mathrm{HOMA} \% \mathrm{~B}$ of T2DM patients was significantly lower than the control subjects $(p<0.001)$ (Table 2$)$. The median (range) HOMA\%S of control subjects and T2DM patients were 44.2 (9.8-339.4) and 32.8 (14.3-154.7), respectively. The median $\mathrm{HOMA} \% \mathrm{~S}$ of T2DM patients was significantly lower than the control subjects $(p<0.05)$ (Table 2$)$. The median (range) HOMA-IR of control subjects and T2DM patients were 3.5 (0.5-11.4) and 5.8 (1.0-28.3), respectively. The median HOMA-IR of T2DM patients was significantly higher than the control subjects $(p<0.001)$ (Table 2$)$.

Table 1. Anthropometric measurements of the study subjects

\begin{tabular}{lccc}
\hline Variables & $\begin{array}{c}\text { Control subjects } \\
(\mathrm{n}=74)\end{array}$ & $\begin{array}{c}\text { T2DM patients } \\
(\mathrm{n}=66)\end{array}$ & $\boldsymbol{p}$ values \\
\hline $\begin{array}{l}\text { Age }(\text { years }) \\
\text { (Mean } \pm \mathrm{SD})\end{array}$ & $42.5 \pm 9.2$ & $48.5 \pm 8.1$ & 0.0001 \\
$\mathrm{BMI}\left(\mathrm{kg} / \mathrm{m}^{2}\right)$ & $25.0 \pm 3.6$ & $25.9 \pm 3.6$ & 0.172 \\
\hline
\end{tabular}

Table 2. Glycemic status of the study subjects

\begin{tabular}{lllr}
\hline Variables & $\begin{array}{l}\text { Control subjects } \\
(\mathrm{n}=74)\end{array}$ & $\begin{array}{l}\text { T2DM patients } \\
(\mathrm{n}=66)\end{array}$ & $\boldsymbol{p}$ values \\
\hline $\begin{array}{l}\text { Fasting Serum Glucose } \\
(\mathrm{mmol} / \mathrm{L})\end{array}$ & $5.3(4.2-6.0)$ & $7.0(4.3-15.4)$ & 0.0001 \\
$\begin{array}{l}\text { Fasting Serum Insulin } \\
(\mu \mathrm{IU} / \mathrm{mL})\end{array}$ & $14.7(1.9-45.9)$ & $18.1(4.1-42.8)$ & 0.214 \\
HOMA\%B & $160.1(33.4-493.4)$ & $100.5(17.7-349.3)$ & 0.0001 \\
HOMA\%S & $44.2(9.8-339.4)$ & $32.8(14.3-154.7)$ & 0.036 \\
HOMA-IR & $3.5(0.5-11.4)$ & $5.8(1.0-28.3)$ & 0.0001 \\
\hline
\end{tabular}




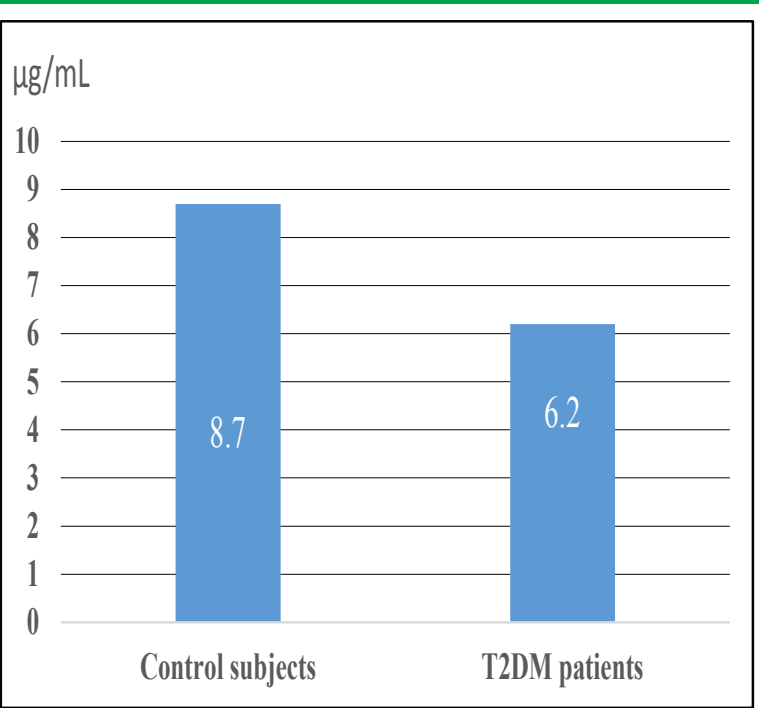

Fig 1. Serum adiponectin level in the study subjects.

\section{Discussion}

The physiological role of adiponectin is not yet fully understood, but it is now generally accepted that it has a protective role against the development of lifestyle disorders related to insulin resistance and atherosclerosis. Insulin resistance is one of the basic defects of T2DM and serum adiponectin level is inversely associated with insulin resistance. This study was aimed to assess the serum adiponectin level in Bangladeshi T2DM patients. Serum adiponectin, serum insulin, insulin secretory capacity (HOMA\%B), insulin sensitivity (HOMA\%S) and insulin resistance (HOMA-IR) of 66 T2DM patients and 74 healthy control subjects were measured. The median (range) serum adiponectin $(\mu \mathrm{g} / \mathrm{mL})$ of the control subjects was $8.7(0.8-16.0)$ which was within normal range $(4-14 \mu \mathrm{g} / \mathrm{mL}){ }^{9,10}$ This result was also compatible with one study done in Bangladeshi population (1.9-19.0 $\mu \mathrm{g} / \mathrm{mL}){ }^{27}$ Lower limit of serum adiponectin level in this study was below the normal level of previous studies. It may be due to small sample size, age difference, BMl difference. The median (range) serum adiponectin $(\mu \mathrm{g} / \mathrm{mL})$ of the T2DM patients was 6.2 (1.1-22.4). The result was consistent with the other studies. ${ }^{9,10}$ The result was also compatible with IGR population in Bangladesh. ${ }^{27}$ The serum adiponectin level of T2DM patients was significantly lower than the control subjects $(p<0.001)$. It indicates that low serum adiponectin level is associated with T2DM in Bangladeshi population. From group difference analysis, it seems evident that serum adiponectin has an inverse association with T2DM. This findings was consistent with other studies. ${ }^{28-30,32,33}$ The median HOMA\%B of T2DM patients was significantly lower than the control subjects $(p<0.001)$. It indicates that T2DM patients in this study had insulin secretory defects. The median HOMA\%S of T2DM patients was significantly lower than the control subjects $(p<0.05)$. The median (range) HOMA-IR of control subjects and T2DM patients were 3.5 (0.5-11.4) and 5.8 (1.0-28.3). The median HOMA-IR of T2DM patients was significantly higher than the control subjects $(p<0.001)$. These findings indicate that T2DM patients in this study had insulin resistance. Impairment of insulin secretion and defects in insulin action frequently coexist in the same T2DM patients. ${ }^{4}$ From the findings of this study, it may be concluded that T2DM patients have both insulin secretory defects and insulin resistance, and serum adiponectin level is lower in T2DM patients in Bangladeshi population.

\section{References}

1. Wild S, Roglic G, Green A, Sicree R, King $H$. Global prevalence of diabetes: estimates for the year 2000 and projections for 2030. Diabetes Care 2004;27:1047-53.

2. Ghaffar A, Reddy KS, Singhi M. Burden of non-communicable diseases in South Asia. BMJ 2004;328:807-10.

3. Sayeed MA, Hussain MZ, Banu A, Rumi MA, Azad KAK. Prevalence of diabetes in a suburban population of Bangladesh. Diabetes Res Clin Pract 2007;34:149-55.

4. American Diabetes Association (ADA). Diagnosis and classification of diabetes mellitus. Diabetes Care 2004;27(1):5-10.

5. Wilding JPH. Obesity and nutritional factors in the pathogenesis of type 2 diabetes mellitus. Textbook of Diabetes. 3rd edn. Pickup JC. Editor. Oxford, UK, Blackwell Science Ltd., 2003.

6. Guerre-Millo M. Adipose tissue and adipokines: for better or worse. Diabetes Metab 2004;30:13-9. 
7. Trayhurn P, Wood IS. Signaling role of adipose tissue: adipokines and inflammation in obesity. Biochem Soc Trans 2005;33:1078-81.

8. Menzaghi C, Trischitta V, Doria A. Genetic influences of adiponectin on insulin resistance, type 2 diabetes, and cardiovascular disease. Diabetes 2007;56(5):1198-209.

9. Arita $\mathrm{Y}$, Kihara $\mathrm{S}$, Ouchi $\mathrm{N}$, et al. Paradoxical decrease of an adipose-specific protein, adiponectin, in obesity. Biochem Biophys Res Commun 1999;257:79-83.

10. Hotta K, Funahashi T, Arita $\mathrm{Y}$, et al. Plasma concentrations of a novel, adipose-specific protein, adiponectin, in type 2 diabetic patients. Arterioscler Thromb Vasc Biol 2000;20:1595-99.

11. Funahashi T, Matsuzawa Y. Hypoadiponectinemia: a common basis for diseases associated with overnutrition. Curr Atheroscler Rep 2006;8:433-8.

12. Okamoto $Y$, Arita $Y$, Nishida $M$, et al. An adipocyte-derived plasma protein, adiponectin, adheres to injured vascular walls. Horm Metab Res 2000;32:47-50.

13. Ouchi N, Kihara S, Arita Y, et al. Novel modulator for endothelial adhesion molecules: adipocyte-derived plasma protein adiponectin. Circulation 1999; 100:2473-76.

14. Antoniades C, Antonopoulos AS, Tousoulis D, Stefanadis C. Adiponectin: from obesity to cardiovascular disease. Obes Rev 2009;10:269-79.

15. Ouchi N, Kihara S, Arita Y, et al. Adiponectin, an adipocyte-derived plasma protein, inhibits endothelial NF-K $B$ signaling through a cAMP-dependent pathway. Circulation 2000;102:1296-301.

16. Zhao YF, Feng DD, Chen C. Contribution of adipocyte-derived factors to beta-cell dysfunction in diabetes. Int $\mathrm{J}$ Biochem Cell Biol 2006;38:804-19.

17. Li S, Shin JJ, Ding EL, van Dam RM. Adiponectin levels and risk of type 2 diabetes: a systematic review and metaanalysis. JAMA 2009;302:179-88.
17. Li S, Shin JJ, Ding EL, van Dam RM. Adiponectin levels and risk of type 2 diabetes: a systematic review and meta-analysis. JAMA 2009;302:179-88.

18. Sattar N, Wannamethee SG, Forouhi N. Novel biochemical risk factors for type 2 diabetes: pathogenic insights or prediction possibilities? Diabetologia 2008;51(6):926-40.

19. Jalovaara K, Santaniemi M, Timonen M, et al. Low serum adiponectin level as a predictor of impaired glucose regulation and type 2 diabetes mellitus in a middle-aged Finnish population. Metabolism 2008;57(8):1130-34.

20. Snehalatha C, Ramachandran A, Mukesh $B$, et al. Plasma adiponectin is an independent predictor of type 2 diabetes in Asian Indians. Diabetes Care 2003;26:3226-29.

21. Lindsay RS, Funahashi T, Hanson RL, et al. Adiponectin and development of type 2 diabetes in the Pima Indian population. Lancet 2002;360:57-8.

22. Zinnat R, Junaid $M M$, Khan $A H$, Chowdhury HS, Ali L. Insulin secretory dysfunction and insulin resistance in Bangladeshi obese Type 2 diabetic subjects. Diabetes Metab 1999; 29:4S103.

23. Junaid MM. Insulin resistance and insulin secretory dysfunction in obese Bangladeshi type 2 diabetic subjects [M Phil Thesis]. Dhaka: University of Dhaka; 2000.

24. Al-Mahmood AK, Hassan Z, Zinnat R, Ali L. Insulin secretion and insulin sensitivity in Bangladeshi type 2 diabetic subjects. Int Med J 2007;14:295-8.

25. Mojlish UKFK. Role of resistin in pathophysiology of type 2 diabetes mellitus in Bangladeshi population [MPhil Thesis]. Dhaka: University of Dhaka; 2008.

26. Islam N, Hossain M, Hafizur RM, et al. Fasting glucose to adiponectin ratio is associated with the development of type 2 diabetes mellitus. J Diabetol 2011;3:11-8.

27. Yamauchi T, Kamon J, Waki H, et al. The fat-derived hormone adiponectin 
reverses insulin resistance associated with both lipoatrophy and obesity. Nature Med 2001;7:941-6.

28. Nakano Y, Tobe T, Choi-Miura NH, Mazda $\mathrm{T}$, Tomita M. Isolation and characterization of GBP28, a novel gelatin-binding protein purified from human plasma. J Biochem 1996; 120:803-12.

29. Spranger J, Kroke A, Mohlig $M$, et al. Adiponectin and protection against type 2 diabetes mellitus. Lancet 2003;361:226-8.

30. Annuzzi G, Bozzetto L, Patti L, et al. Type 2 diabetes mellitus is characterized by reduced post prandial adiponectin response: a possible link with diabetic postprandial dyslipidemia. Metabolism 2010;59(4):567-74.

31. Winer JC, Zern TL, Taksali SE, et al. Adiponectin in childhood and adolescent obesity and its association with inflammatory markers and components of the metabolic syndrome. J Clin Endocrinol Metab 2006;91(11):4415-23.

32. Chandran M, Phillips SA, Ciaraldi T, Henry RR. Adiponectin: more than just another fat cell hormone? Diabetes Care 2003;26:2442-50.

\section{Suggestion for citation of the above:}

Eva SN, Molla GM, Sunyal DK, Zinnat R. Type 2 diabetes mellitus is associated with lower serum adiponectin level in Bangladeshi population. Mediscope 2015;2(2):16-21. 